Jurnal At-Tibyan: Jurnal Ilmu Alqur'an dan Tafsir Volume 5 No. 1, Juni 2020 (h.104-119)

P ISSN 2442-594X | E ISSN 2579-5708

http://journal.iainlangsa.ac.id/index.php/tibyan

\title{
TAFSIR AKADEMIK KARYA MAHMUD YUNUS: CORAK ILMIAH, SOSIAL DAN INTELEKTUAL DALAM TAFSIR AL-QUR'AN AL-KARIM
}

\author{
Academic Tafsir Work Of Mahmud Yunus: Scientific, Social And Intellectual Types \\ In Al-Qur'an Al-Karim Tafsir
}

Nurus Syarifah

Program Studi Interdisciplinary Islamic Studies

Pascasarjana UIN Sunan Kalijaga Yogyakarta

nurussyarifah29@gmail.com

\begin{tabular}{|l|l|l|}
\hline \multicolumn{2}{|c|}{ DOI: $10.32505 /$ tibyan.v5i1.1157 } \\
\hline Submitted: 07-10-2019 & Revised: 22-06-2020 & Accepted: 26-06-2020 \\
\hline
\end{tabular}

\begin{abstract}
:
This article describes the academic aspects of the interpretation of Mahmud Yunus which is named Tafsir Al-Qur'an al-Karim. This interpretation is one of the pioneers of Indonesian-language interpretation works that are widely used by the majority of Muslims in Indonesia. He dared to introduce the use of Latin letters for translation and interpretation of the Qur'an. The method used in this research is descriptive method. The conclusion of this study is that the academic aspects of Mahmud Yunus' interpretation work include scientific, social and intellectual styles. The scientific style in its interpretation is a new style that is associated with developing science, so its interpretation seems to emphasize the close relationship between the Qur'an and the development of science and technology which are the main characteristics of modern thought. The social and intellectual patterns are more demonstrated by Mahmud Yunus through the use of elements of common expressions, as well as traditions, customs and socio-cultural phenomena in their interpretation.
\end{abstract}

Keywords: Mahmud Yunus, Tafsir Al-Qur'an al-Karim, Academic Aspects.

\begin{abstract}
Abstrak:
Artikel ini menjelaskan tentang aspek akademik dari tafsir Mahmud Yunus yang diberi nama Tafsir Al-Qur'an al-Karim. Tafsir ini merupakan salah satu pionir karya tafsir berbahasa Indonesia yang banyak digunakan oleh mayoritas umat Islam di Indonesia. Ia berani memperkenalkan pemakaian huruf Latin untuk terjemahan dan tafsir Al-Qur'annya. Metode yang digunakan dalam penelitian ini adalah metode deskriptif. Adapun kesimpulan dari penelitian ini bahwa aspek akademik dalam karya tafsir Mahmud Yunus ini meliputi corak ilmiah, corak sosial dan corak intelektual. Corak ilmiah dalam penafsirannya
\end{abstract}

Hak Cipta @ 2020. Dimiliki oleh Penulis, dipublikasikan oleh Jurnal At-Tibyan: Jurnal Ilmu Alqur'an dan Tafsir.

Artikel dengan akses terbuka. Lisensi: CC-BY

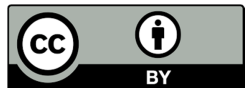


merupakan sebuah corak baru yang dikaitkan dengan ilmu pengetahuan yang sedang berkembang, sehingga penafsirannya terkesan menegaskan dan menunjukkan hubungan yang erat antara Al-Qur'an dengan perkembangan ilmu pengetahuan dan teknologi yang mana hal ini menjadi ciri utama pemikiran modern. Adapun corak sosial dan corak intelektual lebih ditunjukkan Mahmud Yunus melalui penggunaan unsur ungkapan umum, maupun tradisi, adat dan fenomena sosial budaya dalam penafsirannya.

Kata Kunci: Mahmud Yunus, Tafsir Al-Qur'an al-Karim, dan Aspek Akademik.

\section{Pendahuluan}

Islam telah menjadi agama mayoritas bangsa-bangsa Asia Tenggara, atau populer disebut Asean. Secara inklusif, begitu Islam masuk ke suatu wilayah, maka penafsiran kitab suci Al-Qur'an secara otomatis ikut masuk ke wilayah tersebut. Hal ini dikarenakan, Islam tidak dapat dipahami tanpa penafsiran kitab sucinya, apalagi bagi bangsa-bangsa 'ajam (non-Arab) seperti bangsa Asean. ${ }^{1}$ Begitupun yang terjadi di Indonesia ketika Islam masuk, mulai bermunculan berbagai kitab penerjemahan dan penafsiran Al-Qur'an dengan menggunakan bahasa Indonesia. Semua ini dimaksudkan untuk mempermudah bagi siapapun masyarakat Indonesia yang ingin mempelajari dan memahami Al-Qur'an, walaupun pada awal penerjemahan dan penafsiran ke dalam bahasa Indonesia sempat dinyatakan haram oleh para ulama Islam saat itu. ${ }^{2}$

Merujuk pada apa yang ditulis Howard M. Federspiel tentang periodisasi sejarah perkembangan penerjemahan dan penafsiran Al-Qur'an ke dalam bahasa Indonesia, ia membaginya menjadi tiga generasi. Generasi pertama mulai dari sekitar abad ke-20 sampai awal tahun 1960-an, ditandai dengan penerjemahan dan penafsiran yang masih terpisah-pisah. Generasi kedua muncul pada pertengahan tahun 1960, merupakan penyempurnaan atas upaya generasi pertama, penerjemahan lengkap ini biasanya memiliki beberapa catatan, catatan kaki, terjemahan kata per-kata, dan kadang disertai dengan suatu indeks yang sederhana. Adapun generasi ketiga mulai muncul pada tahun 1970-an, merupakan penafsiran yang lengkap, seringkali memberikan komentarkomentar yang luas terhadap teks bersamaan terjemahannya, memiliki bagian pengantar dan indeks yang memperluas isi, tema-tema atau asbab al-nuzul Al-Qur'an. ${ }^{3}$

Menurut Federspiel ada beberapa karya yang cukup representatif dalam mewakili tafsir generasi kedua, yaitu al-Furqon karya Ahmad Hassan, Tafsir Al-Qur'an karya Hamidy, dan Tafsir Al-Qur'an al-Karim karya Mahmud Yunus. ${ }^{4}$ Berbeda dengan periodisasi yang disajikan oleh Islah Gusmian, ketiga tafsir ini masuk dalam

\footnotetext{
${ }^{1}$ Nashruddin Baidan dan Erwati Aziz, Perkembangan Tafsir Al-Qur'an di Asia Tenggara (Yogyakarta: Pustaka Pelajar, 2019), 1-2.

${ }^{2}$ Howard M. Federspiel, Kajian Al-Qur'an di Indonesia; dari Mahmud Yunus hingga Quraish Shihab, terj. Tajul Arifin (Bandung: Penerbit Mizan, 1996), 25. Lebih lanjut juga lihat Mahmud Yunus, Tafsir Al-Qur'an al-Karim (Djakarta: PT Hidakarya Agung, 1983), iii.

${ }^{3}$ Federspiel, Kajian Al-Qur'an di Indonesia, 129.

${ }^{4}$ Federspiel, Kajian Al-Qur'an di Indonesia, 129.
} 
kategorisasi periode pertama yang ia susun. Menurutnya, ketiga tafsir ini muncul pada pertengahan dan akhir tahun 1950-an. Hal ini sesuai dengan kategorisasi yang ia susun, yang mana periode pertama memiliki rentang waktu awal abad ke-20 sampai tahun 1960. Adapun periode kedua menurut Islah Gusmian yaitu antara tahun 1970-an sampai tahun 1980-an. Sedangkan rentang waktu untuk periode ketiga adalah mulai tahun 1990-an sampai seterusnya. ${ }^{5}$

Adanya perbedaan periodisasi di atas dapat disebabkan beberapa hal, di antaranya pemilahan tahun perperiode yang berbeda, sudut pandang yang berbeda terhadap objek kajian, dan juga perolehan data yang berbeda oleh para peneliti. ${ }^{6}$ Walaupun terdapat perbedaan periodisasi antar peneliti, tidak dapat dipungkiri bahwa tafsir karya Mahmud Yunus merupakan salah satu karya monumental pada kelompok periodenya maupun generasinya.

Karya tafsir Mahmud Yunus ini memudahkan para pembacanya untuk berinteraksi dengan Al-Qur'an. ${ }^{7}$ Hal ini karena tafsir yang ia susun memang berusaha agar makna Al-Qur'an dapat diterima oleh seluruh kalangan masyarakat. ${ }^{8}$ Karya ini merupakan salah satu pionir dalam karya tafsir berbahasa Indonesia yang banyak digunakan oleh orang-orang berbahasa Melayu ${ }^{9}$ karena penggunaan huruf Latin dalam penerjemahan dan penafsiran Al-Qur'annya. Karenanya, Mahmud Yunus juga dianggap sebagai pelopor pola baru penulisan tafsir Al-Qur'an di Indonesia. Pola baru lain yang ditemukan dalam karya tafsirnya ini menjadikannya tergolong tafsir akademik. Sehingga dalam tulisan ini akan membahas aspek-aspek akademik dalam Tafsir AlQur'an al-Karim sebagai tafsir akademik karya Mahmud Yunus.

\section{Biografi Mahmud Yunus}

\section{Riwayat Hidup dan Pendidikan}

Mahmud Yunus lahir pada hari Sabtu di Sungayang, Batusangkar, Sumatra Barat, tanggal 10 Februari $1899 \mathrm{M}$ bertepatan dengan 30 Ramadan 1316 H. Ia Berasal dari keluarga yang agamis. Ayahnya bernama Yunus bin Incek, pengajar di surau. Ibunya bernama Hafsah binti Imam Samiun. Kakek Ibunya yaitu Engku Gadang M. Tahir bin Ali, merupakan seorang pendiri dan pengasuh surau di wilayah tersebut. ${ }^{10}$ Selain mengajar di surau dan menjadi imam dengan sebutan Imam Nagari, ayah Mahmud Yunus berasal dari suku Mandailing. Ia juga bekerja sehari-hari sebagai petani. Adapun sang ibu buta huruf karena tidak pernah mengenyam pendidikan di

${ }^{5}$ Taufikurrahman, "Dinamika Kajian Al-Qur'an di Indonesia," Ibn Abbas: Jurnal Ilmu Al-Qur'an dan Tafsir 2, no. 1 (2019): 218.

${ }^{6}$ Taufikurrahman, “Dinamika Kajian Al-Qur'an di Indonesia,”, 219.

${ }^{7}$ Rithon Igisani, “Kajian Tafsir Mufassir di Indonesia,"Jurnal Potret 22, no. 1 (2018) : 11-31.

${ }^{8}$ Zulyadain, "Kerangka Paradigmatik Tafsir Al-Qur' an Al-Karim Karya Mahmud Yunus,"Jurnal AlA'raf 15, no. 1 (2018): 127-145.

${ }^{9}$ M. Amursid dan Amaruddin Asra, "Studi Tafsir al-Qur'an al-Karim Karya Mahmud Yunus,"Jurnal Syahadah, 3, no. 2 (2015): 2.

${ }^{10}$ Saiful Amin Ghofur, Profil Para Mufasir al-Qur'an, (Yogyakarta: Pustaka Insan Madani, 2008), 197. 
desanya, memiliki panggilan Posa dari suku Chaniago, ${ }^{11}$ dan pekerjaan hariannya menenun kain tradisional Minangkabau. ${ }^{12}$ Mahmud Yunus sejak kecil mulai belajar AlQur'an pada kakeknya. ${ }^{13}$ Ia merupakan satu-sat unya anak laki-laki dalam keluarganya. Mahmud Yunus mempunyai lima orang istri dan dengannya dikarunai 18 orang anak. ${ }^{14}$ Awal tahun 1970 kesehatan Mahmud Yunus menurun dan keluar-masuk rumah sakit, dan akhirnya ia menghembuskan napas terakhirnya pada tahun 1982.

Sejak kecil Mahmud Yunus sudah dididik dalam lingkungan yang agamis. Ia belajar Al-Qur'an dan praktik ibadah serta ilmu-ilmu ke-Islaman lainnya dengan kakeknya, sejak tahun 1906 M. Pernah masuk Sekolah Rakyat. tetapi hanya sampai tahun keempat. Selanjutnya ia masuk Madrasah School yang didirikan oleh H. M. Thaib Umar, seorang tokoh pembaru Islam di Minangkabau. Prestasi Mahmud di Madrasah sangat cemerlang, sehingga ia dipercaya untuk mengajar beberapa kitab, antara lain al-Mahally, Alfiyah ibn Aqil, dan Jam' al-Jawami. Saat itu usianya baru 16 tahun. ${ }^{15}$ Selanjutnya Mahmud Yunus belajar di Universitas al-Azhar Kairo, Mesir, pada tahun 1924 M. Ia pun melanjutkan studi ke Dar al-'Ulum, Universitas Kairo, Mesir. Pada tahun 1929 ia lulus dan kembali ke kampung halamannya. ${ }^{16}$

\section{Karir dan Karya-Karya}

Karir Mahmud Yunus di antarnya mendirikan dan memimpin lembaga pendidikan Islam bernama al-Jami'ah al-Islamiyyah di Sungayang dan Normal Islam di Padang pada tahun 1931 M. Ia juga memimpin Sekolah Islam Tinggi (SIT) di Padang, mendirikan Akademi Dinas Ilmu Agama (ADIA) dan sekaligus menjadi dekannya tahun 1957-1960. Mahmud Yunus juga berhasil mendirikan dan memimpin Sekolah Menengah Islam (SMI) di Bukittinggi. Tahun 1960, ia diangkat menjadi Dekan Fakultas Tarbiyah UIN Syarif Hidayatullah Jakarta, dan menjadi Rektor IAIN Imam Bonjol Padang. ${ }^{17}$ Adapun karya-karya yang dihasilkan Mahmud Yunus di bidang pendidikan, bahasa Arab, fikih, tafsir, akhlak, sejarah, dan ada juga karya di bidang lainnya. Karyanya yang paling monumental dan paling banyak berpengaruh adalah Tafsir Al-Qur'an al-Karim, terbit pada tahun 1938 M dan sudah mengalami cetak berulang kali. ${ }^{18}$

${ }^{11}$ Arif Iman Mauliddin, Unsur Lokal dalam Tafsir Al-Qur'an Karim Karya Mahmud Yunus, (Yogyakarta: Tesis Mahasiswa UIN Sunan Kalijaga, 2019), 21.

${ }^{12}$ Malta Rina, Pemikiran dan Karya-Karya Prof. Dr. H. Mahmud Yunus tentang Pendidikan Islam (1920-1982), (Padang: Ilmu Sejarah Pascasarjana UNAND, 2011), 3.

${ }^{13}$ Herry Mohammad, dkk, Tokoh-Tokoh Islam yang Berpengaruh Abad 20, Cet ke-2, (Jakarta: Gema Insani, 2008), 85-86.

${ }^{14}$ Malta Rina, Pemikiran dan Karya-Karya Prof. Dr. H. Mahmud Yunus, 170-174.

${ }^{15}$ Lebih lanjut lihat Herry Mohammad, dkk, Tokoh-Tokoh Islam, 85-86. Lihat juga Saiful Amin Ghofur, Profil Para Mufasir al-Qur'an, 197-199.

${ }^{16}$ Lebih lanjut lihat Herry Mohammad, dkk, Tokoh-Tokoh Islam, 85-86. Lihat juga Saiful Amin Ghofur, Profil Para Mufasir al-Qur'an, 197-199.

${ }^{17}$ Lebih lanjut lihat Herry Mohammad, dkk, Tokoh-Tokoh Islam, 86-91. Lihat juga Saiful Amin Ghofur, Profil Para Mufasir al-Qur'an, 199-200.

${ }^{18}$ Lebih lanjut lihat Herry Mohammad, dkk, Tokoh-Tokoh Islam, 86-91. Lihat juga Malta Rina, Pemikiran dan Karya-Karya Prof. Dr. H. Mahmud Yunus, 176-180. Lihat juga Saiful Amin Ghofur, 


\section{Tafsir Al-Qur'an al-Karim Karya Mahmud Yunus \\ Latar Belakang Penulisan Kitab}

Menurut keterangan Mahmud Yunus, karya tafsirnya ini merupakan hasil "penyelidikan" yang dilakukan mendalam oleh dirinya sendiri selama kurang lebih 53 tahun, sejak ia berusia 20 hingga 73 tahun. Selama ia menyelesaikan kitabnya, muncul berbagai protes dan reaksi dari berbagai kalangan yang menantang kegiatannya dalam menerjemahkan dan menafsirkan Al-Qur'an ke dalam bahasa Indonesia. Banyak yang menganggap bahwa hal tersebut langka dan haram dilakukan. ${ }^{19}$

Penulisan kitab tafsir ini dimulai pada tahun 1922 M dan berhasil diterbitkan untuk juz pertama, kedua dan ketiga. Selang dua tahun, pada 1924 M Mahmud Yunus menghentikan penulisan karena ia ingin melanjutkan studi ke al-Azhar Kairo, Mesir. Saat belajar di Mesir inilah, Mahmud Yunus mengetahui tentang kebolehan menerjemahkan dan menafsirkan Al-Qur'an ke dalam bahasa asing -selain bahasa Arab. Hal ini boleh dilakukan dengan tujuan agar bangsa non-Arab yang tidak paham dengan bahasa Arab juga dapat memahami dan mempelajarinya. Karenanya, setelah Mahmud Yunus pulang dari Mesir, ia pun melanjutkan penulisannya pada tahun 1935 M. Pada saat itu, Mahmud Yunus pun berhasil menamai kitab ini dengan "Tafsir AlQur'an al-Karim". Selanjutnya, penafsiran ini diterbitkan satu juz tiap dua bulan. Adapun dalam penerjemahan juz tujuh sampai juz 18 dibantu oleh H. M. K. Bakry, dan akhirnya pada bulan April 1938 M, 30 juz Al-Qur'an pun khatam. ${ }^{20}$

Karya tafsir ini, seperti yang diakui Mahmud Yunus, berorientasi mulia, dalam artian 'menjelaskan petunjuk-petunjuk Al-Qur' an agar diamalkan oleh kaum Muslimin khususnya dan umat manusia pada umumnya, sebagai petunjuk universal." Menurutnya pula, tujuan dari penulisan tafsir ini adalah untuk memberikan keterangan dan penjelasan tentang petunjuk-petunjuk Al-Qur'an agar dapat dimengerti dengan mudah, cepat, dan dapat dipraktikkan masyarakat dalam kehidupan sehari-hari. Selain itu, karya ini juga disuguhkan untuk kalangan pelajar dan mahasiswa sebagai bahan praktis mempelajari bahasa Al-Qur'an dan juga untuk masyarakat umum yang ingin mendalami isi kitab suci. ${ }^{21}$ Dari sini tersirat betapa Mahmud ingin menjadikan karyanya ini sebagai tafsir yang bersahaja, praktis, dan dapat dipelajari semua orang.

\section{Metodologi Penafsiran}

Tafsir Al-Qur'an al-Karim ini menggunakan metode penafsiran ijmali (global). ${ }^{22}$ Adapun sumber rujukan tafsirnya sebagai berikut; tafsir al-Thabari juz 1 halaman 42, tafsir Ibnu Katsir juz 1 halaman 3, tafsir al-Qasimy juz 1 halaman 7, Fajrul Islam juz 1

Profil Para Mufasir al-Qur'ain, 200. Lihat juga Sulaiman Ibrahim, Pendidikan dan Tafsir; Kiprah Mahmud Yunus dalam Pembaruan Islam, (Jakarta: LEKAS, 2011), 42.

${ }^{19}$ Lebih lanjut lihat Mahmud Yunus dalam mukadimah Tafsir Al-Qur'an al-Karim, iii-vii. Lihat juga Sulaiman Ibrahim, Pendidikan dan Tafsir, 84.

${ }^{20}$ Lebih lanjut lihat Mahmud Yunus dalam mukadimah Tafsir Al-Qur'an al-Karim, iii-vii. Lihat juga Sulaiman Ibrahim, Pendidikan dan Tafsir, 84.

${ }^{21}$ Yunus, Tafsir Al-Qur'an al-Karim, iii-vii.

${ }^{22}$ Ghofur, Profil Para Mufasir al-Qur'an, 200-201. 
halaman 199, dan Zhuhurul Islam juz 2 halaman 40-43 dan juz 3 halaman 37. ${ }^{23}$ Sedangkan, sumber ataupun materi penafsirannya mengombinasikan dua metode, yaitu penafsiran dari teks (bi al-ma'tsur) dan penafsiran dari akal (bi al-ra'y). ${ }^{24}$ Metodemetode tersebut di antaranya: $\left.{ }^{25} 1\right)$ Menafsirkan ayat Al-Qur'an dengan Al-Qur'an, 2) Menafsirkan ayat Al-Qur'an dengan hadis Rasulullah saw., 3) Menafsirkan dengan perkataan sahabat, tetapi khusus dengan menjelaskan sebab-sebab turunnya ayat AlQur'an, 4) Menafsirkan dengan perkataan tabiin, jika mereka berijmak atas suatu tafsir, 5) Menafsirkan dengan mengemukakan kata-kata pepatah, 6) Menafsirkan dengan ijtihad bagi yang ahli, atau melalui pandangan akal, 7) Menafsirkan dengan bahasa Arab atau dengan makna kalimah, 8) Menafsirkan ayat-ayat Al-Qur'an dengan mengemukakan kisah nabi-nabi dan umat-umat terdahulu. ${ }^{26}$

\section{Karakteristik Kitab}

Sebagai sebuah karya, Tafsir Al-Qur'an al-Karim mempunyai karakteristik terkait beberapa aspek, yaitu sistematika penerjemahan/ penafsiran, sistematika penyusunan, teknik penerjemahan dan keterangan (catatan kaki), analisis istilah dan konsep-konsep, serta kandungan kesimpulan isi Al-Qur'an. ${ }^{27}$

Pertama yaitu sistematika penerjemahan/ penafsiran. Format terjemahannya dengan meletakkan posisi teks Al-Qur'an di sebelah kanan dan terjemahannya di sebelah kiri. Format seperti ini memudahkan orang untuk mengetahui terjemah dari masing-masing ayat. Pada sisi lain, Mahmud Yunus menguraikan objek tertentu dengan cukup panjang. ${ }^{28}$

${ }^{23}$ Yunus, Tafsir Al-Qur'an al-Karim, iii-vii.

${ }^{24}$ Tri Hermawan, Putri Rafa Salihah, Muhammad Hafizh, “The Concept of Women's Dress in Tafsir Nusantara: A Comparative Study of Four Indonesian Exegeses," Ulumuna: Journal of Islamic Studies 21, no. 2 (2017): 370-390.

${ }^{25}$ Mahmud Yunus, Tafsir Al-Qur'an al-Karim, h. iii-vii. Lihat juga Khader Ahmad dkk, "Ketokohan Mahmud Yunus dalam Bidang Tafsir Al-Qur'an: Kajian terhadap Kitab Tafsir Quran Karim," The 2nd Annual International Qur'anic Conference, Centre of Quranic Research (CQR), Tahun 2012, 202-207.

${ }^{26}$ Howard M. Federspiel menambahkan beberapa metode yang digunakan Mahmud Yunus dalam menulis kitab Tafsir Al-Qur'an al-Karim, sebagai berikut; 1) Dalam penafsiran, Mahmud Yunus memberi keterangan singkat terhadap istilah-istilah yang berada dalam Al-Qur'an. contoh dalam hal ini, seperti kata $R a b b$ yang dalam bahasa Arab memiliki arti percipta dan pemelihara, pengatur dan pendidik, yang menata dan mengatur segala sesuatu dalam cara yang paling baik, bijak dan sempurna. Oleh karena itu, Rabb berarti "pemimpin atau pengarah" dalam bahasa Indonesia, meskipun pemaknaan tersebut tidak memberikan arti yang pasti. 2) Mahmud Yunus memberikan informasi mengenai konsepkonsep tentang dasar keyakinan dan praktik-praktik yang ditemukan dalam Al-Qur'an. 3) Memberikan penjelasan-penjelasan tentang poin-poin penting yang terdapat dalam setiap surah Al-Qur'an, sebagai petunjuk bagi pembacanya. 4) Sekitar $60 \%$ dari catatan kaki yang ditemukan dalam tafsir ini digunakan untuk menjelaskan kata-kata atau kalimat tertentu dan untuk mengungkap kembali teks agar lebih jelas maksudnya. 5) Menjelaskan secara singkat tentang proses turun Al-Qur'an, pengumpulan dan pemeliharaannya. 6) Menyajikan daftar kata-kata yang disusun secara alfabetis dengan merujuk pada halaman-halaman tertentu (indeks dan daftar kata). Lebih lanjut lihat Federspiel, Kajian Al-Qur'an di Indonesia, 129-137.

${ }^{27}$ Ibrahim, Pendidikan dan Tafsir, 87-102.

${ }^{28}$ Contoh yang cukup mewakili hal ini adalah ketika Mahmud Yunus menjelaskan makna persatuan

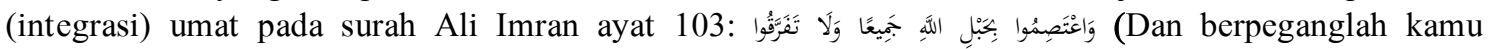
semuanya kepada tali (agama) Allah, dan janganlah kamu bercerai berai). Demikian juga mengenai 
Contoh Format Penerjemahan ${ }^{29}$

\begin{tabular}{|c|c|c|}
\hline \multicolumn{3}{|c|}{ Surah al-Fatihah } \\
\hline \multicolumn{3}{|c|}{ (Pembukaan) } \\
\hline \multicolumn{3}{|c|}{ Diturunkan di Makkah, 7 ayat } \\
\hline 1. & $\begin{array}{l}\text { Dengan nama Allah yang Maha Pengasih lagi } \\
\text { Maha Penyayang. }\end{array}$ & بِسنمِ اللهِ الرَّمَنْنِ الرَّحَِيْم \\
\hline 2. & $\begin{array}{l}\text { Segala puji bagi Allah, (Yang Mendidik) } \\
\text { semesta alam. }\end{array}$ & الحْمْدُ لِلَّهِ رَبِّ الْعَالَمِينَ \\
\hline 3. & Yang Maha Pengasih lagi Maha Penyayang. & 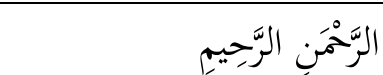 \\
\hline 4. & Lagi mempunyai (penguasa) hari pembalasan. & مَالِكِ يَوْرُ الِّدِينِ \\
\hline 5. & $\begin{array}{l}\text { Hanya Engkaulah yang kami samba dan hanya } \\
\text { kepada Engkaulah kami meminta pertolongan. }\end{array}$ & إِيَّاكَ نَعْبُدُ وَإِيَّاكَكَ نَسْتَعِينُ \\
\hline 6. & Tunjukilah kami jalan yang lurus, & اهْدِنَا الصِّرَاطَ الْمُسنتَقِيَمَ \\
\hline 7. & $\begin{array}{l}\text { yaitu jalan orang-orang yang telah Engkau } \\
\text { berikan nikmat-nikmat kepada mereka. }\end{array}$ & 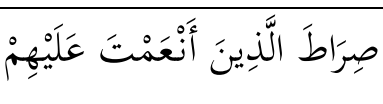 \\
\hline & Sedang mereka itu orang-orang yang dimurkai & غَيْر الْمَغْضُوبِ عَلَيْهِهْْ \\
\hline & dan bukan pula orang-orang yang sesat. & 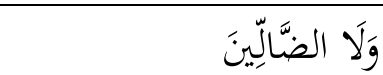 \\
\hline
\end{tabular}

Kedua ialah sistematika penyusunan. Penerjemahan teks Al-Qur'an Mahmud Yunus terdapat 924 halaman. Cover, Lembar Pengesahan dan Pendahuluan menghabiskan tujuh halaman (halaman i-vii). Selebihnya, 27 halaman tambahan (halaman i - xxvii) digunakan sebagai lampiran yang berisi Daftar Surah dan Isi Tafsir, Daftar Isi Surah Berdasarkan Alfabet, dan Daftar Juz-Juz Al-Qur'an -hal ini merupakan suatu terobosan yang tentu sangat membantu pembaca dalam mencari ayat, surah, dan juz Al-Qur'an. Sedangkan pada bagian paling akhir, ia menyertakan karyanya ini dengan 32 halaman khusus berisikan kesimpulan isi Al-Qur'an, menyangkut hukum, etika (akhlak), ilmu pengetahuan, ekonomi, sejarah, dan lain-lain. ${ }^{30}$

Selanjutnya yang ketiga ialah teknik penerjemahan dan keterangan (catatan kaki). Hampir 60 persen karya Mahmud Yunus berisi terjemahan ayat Al-Qur'an dan 40 persen sisanya merupakan keterangan dalam bentuk catatan kaki terhadap beberapa istilah dan konsep agama. Adapun untuk teknik penerjemahan, ia menggunakan teknik penerjemahan harfiah (litera). Walupun demikian, terdapat juga terjemahan maknawi

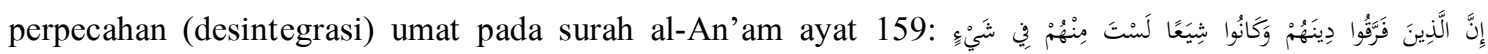
(Sesungguhnya orang-orang yang memecah belah agamanya dan mereka (terpecah) menjadi beberapa golongan, tidak ada sedikit pun tanggung jawabmu terhadap mereka). Hal terpenting dari uraian ini adalah ia berusaha menyisipkan suatu pesan moral kepada para pembacanya agar dalam kehidupan bermasyarakat senantiasa menjaga nilai-nilai kebersamaan dan rasa persatuan.

${ }^{29}$ Mahmud Yunus, Tafsir Al-Qur'an al-Karim, 1.

${ }^{30}$ Iskandar, "Tafsir Qur'an Karim Karya Mahmud Yunus; Kajian atas Karya Tafsir Nusantara," Jurnal Suhuf, Vol. 3, No. 1, 2010, h. 5. Lihat juga Mahmud Yunus, Tafsir Al-Qur'an al-Karim, (Djakarta: PT Hidakarya Agung, 1983). 
yang ditandai dengan dua tanda kurung dan selebihnya dalam bentuk catatan kaki. ${ }^{31}$ Karakteristik keempat selanjutnya yaitu analisis istilah dan konsep-konsep. Mahmud Yunus memiliki kecenderungan ketika menerjemahkan suatu kata (istilah) yaitu dengan menekankan pada pengertian leksikal dan semantik sesuai dengan perkembangan bahasa yang terpakai pada saat Al-Qur' an diturunkan. ${ }^{32}$

Adapun karakteristik yang terakhir adalah kandungan kesimpulan isi Al-Qur'an. Adanya subbab "Kesimpulan Isi Al-Qur'an" pada bagian akhir, kurang lebih 32 halaman, yang mana memuat persoalan umum meliputi hukum, etika, ilmu pengetahuan, ekonomi, sejarah, dan lain-lain. Tujuannya, membantu para pembaca yang ingin menggali lebih jauh hukum-hukum dan pesan penting Al-Qur'an.

\section{Aspek Akademik Tafsir Al-Qur'an Al-Karim}

Aspek akademik dalam kitab tafsir karya Mahmud Yunus ini terlihat dari corakcorak penafsiran yang digunakannya. Corak-corak penafsiran tersebut merupakan corak pembaharuan yang ada di Indonesia, dan Mahmud Yunus merupakan pelopor pembaharuan berbagai corak tersebut. Adapun corak penafsiran yang muncul dari Tafsir Al-Qur'an al-Karim ini adalah corak 'ilmi, corak sosial dan corak intelektual. Corak-corak tersebut banyak menonjolkan sisi ilmiah, ilmu pengetahuan, nilai-nilai dan kondisi sosial, serta moral kehidupan dan juga fenomena pendidikan saat itu. Maka pantas, dan tidak heran jika munculnya corak-corak di atas menjadikan Tafsir AlQur'an al-Karim karya Mahmud Yunus ini termasuk dalam golongan tafsir yang berbasis akademis.

\section{Corak 'Ilmi}

Adanya corak ilmiah dalam kitab tafsir Mahmud Yunus ini sesuai dengan tujuan dalam penulisan karyanya, yaitu untuk menggali hubungan harmoni antara Al-Qur'an sebagai sumber pokok ajaran Islam dan mengelaborasinya dengan ilmu pengetahuan dan teknologi yang menjadi ciri utama modernitas yang semakin hari semakin meningkat. Untuk mempertegas corak ini, pada bagian kitab juga terdapat indeksindeks ayat yang terkait dengan ilmu pengetahuan dan teknologi. ${ }^{33}$

31 Sebagai contoh penerjemahannya pada surah al-Isra' ayat 29: “َّanganlah engkau jadikan tangan engkau terbelenggu ke kuduk engkau (jangan bakhil)". Hal ini terlihat pada ayatayat Al-Qur'an yang menggunakan lafal konotatif. Mahmud juga mengakui bahwa penerjemahan harfiah tidak cukup memadai, sehingga diperlukan penerjemahan maknawi untuk menjelaskan pengertian yang sebenarnya dari suatu ayat.

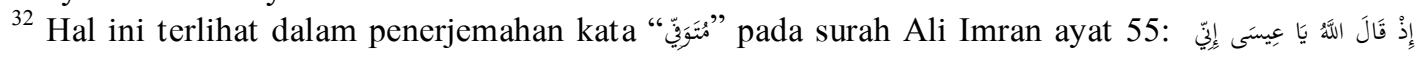

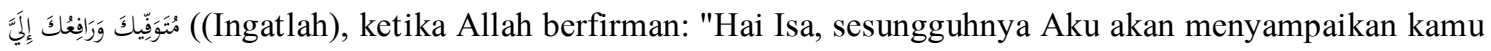

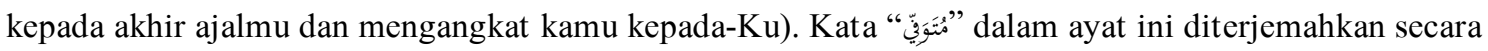
leksikal dengan 'mewafatkan', karena menurutnya pengertian ini yang biasa terpakai dalam bahasa Arab dan tidak ada indikasi lain yang dapat memutarnya pada pengertian lain. Lebih lanjut lihat Iskandar, “Tafsir Qur'an Karim Karya Mahmud Yunus," h. 5.

${ }^{33}$ Arif Iman Mauliddin, Unsur Lokal dalam Tafsir Al-Qur'an Karim, h. 43-44. Lebih lanjut lihat M. Anwar Syarifuddin dan Jauhar Azizy, "Mahmud Yunus: Pelopor Pola Baru Penulisan Tafsir Al-Qur'an Indonesia”, Jurnal Ilmu Ushuluddin, Vol. 2, No. 3, Januari-Juni 2015, 331-332. 
Hal lain yang mendukung adanya corak ilmiah dalam kitab Tafsir Al-Qur'an al-Karim ini di antaranya; pertama, Mahmud Yunus memberikan penjelasan terhadap ayat-ayat Al-Qur'an sesuai perspektif teori ilmiah modern. Kedua, ia menggunakan temuan-temuan dan kemajuan ilmiah modern untuk memperkokoh kemukjizatan AlQur'an dan ketinggian nilai-nilai ajaran Islam. Ketiga, ia tak luput mengemukakan temuan-temuan ilmiah modern sebagai bahan dan materi perbandingan dalam fenomena dan pesan-pesan ajaran Al-Qur'an untuk menyeimbangkannya dengan kondisi yang kekinian. ${ }^{34}$

Corak ilmiah yang mulai dimasukkan Mahmud Yunus sebagai corak baru dalam penafsiran ini, merupakan sebuah pengaruh besar yang didapatkannya dari gagasan pembaruan Muhammad 'Abduh yang diterimanya melalui Rasyid Ridha. Hal demikian, dapat dilihat ketika Mahmud Yunus menuntut ilmu di Mesir, maupun dari tulisan-tulisan dalam majalah al-Manar. ${ }^{35}$ Pengaruh Muhammad 'Abduh terhadap Mahmud Yunus juga dapat terlihat dari aktivitas pergerakan pembaruan Islam di Sumatra yang diikuti oleh Mahmud Yunus yang mana bertujuan untuk menguatkan perkenalannya dengan gagasan-gagasan pembaruan Muhammad 'Abduh dan Muhammad Rasyid Rida lewat majalah al-Manar. ${ }^{36}$

Adapun contoh penafsiran corak ilmiah yang ada di kitab tafsir Mahmud Yunus ini, di antaranya:

Surah al-Fiil ayat 1-5

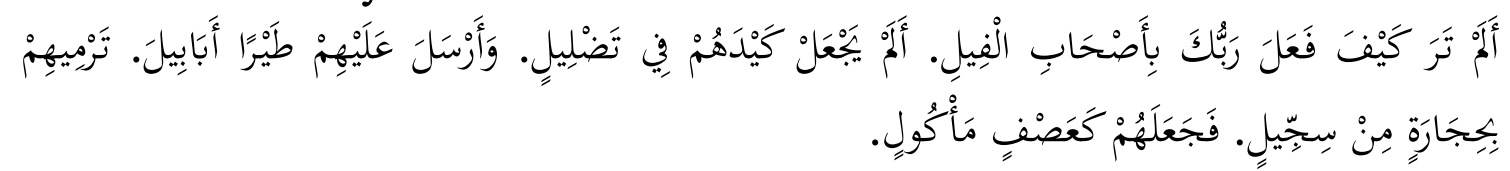

Artinya: "1) Tiadakah engkau tahu, bagaimana Tuhanmu memperbuat terhadap orangorang yang mempunyai gajah. 2) Tiadakah ia menjadikan tipu daya mereka jadi sia-sia. 3) Dan mengirim kepada mereka burung berbondong-bondong. 4) Yang melempar mereka dengan batu dari tanah yang keras. 5) Lalu Allah jadikan mereka seperti daun yang dimakan (ulat)".

Dalam penafsirannya, Mahmud Yunus menjelaskan ayat yang ada di atas bahwa:

"Adapun bala tentara yang bergajah itu, ialah Raja Yaman yang datang ke Negeri Makkah hendak meruntuhkan Ka'bah dengan membawa laskar dan gajah yang

${ }^{34}$ Arif Iman Mauliddin, Unsur Lokal dalam Tafsir Al-Qur'an Karim, 43-44. Lebih lanjut lihat M. Anwar Syarifuddin dan Jauhar Azizy, "Mahmud Yunus: Pelopor Pola Baru Penulisan Tafsir Al-Qur'an Indonesia,", 331-332.

${ }^{35}$ Arif Iman Mauliddin, Unsur Lokal dalam Tafsir Al-Qur'an Karim, 44. Lebih lanjut lihat M. Anwar Syarifuddin dan Jauhar Azizy, "Mahmud Yunus: Pelopor Pola Baru Penulisan Tafsir Al-Qur'an Indonesia," 332.

${ }^{36}$ M. Anwar Syarifuddin dan Jauhar Azizy, "Mahmud Yunus: Pelopor Pola Baru Penulisan Tafsir Al-Qur'an Indonesia," 326. Lebih lanjut dalam jurnalnya dibahas panjang lebar mengenai corak 'ilmi dan contoh-contohnya, tafsir rasional, demitologisasi, dan juga keterpengaruhan Muhammad 'Abduh terhadap Mahmud Yunus. Sedangkan Nama al-Manar pada awalnya adalah nama majalah yang menyuarakan gagasan-gagasan pembaruan Muhammad 'Abduh. Namun atas ide Rasyid Rida akhirnya gagasan-gagasan 'Abduh dikumpulkan dalam sebuah kitab. Itulah cikal bakal kelahiran kitab tafsir alManar. 
kuat. Setelah mereka hampir masuk ke Negeri Makkah, lalu beberapa burung menjatuhkan batu (tanah yang keras), boleh jadi di dalamnya banyak hama penyakit cacar, sehingga mereka semuanya dihinggapi penyakit itu, akhirnya badan mereka hancur luluh seperti daun kayu dimakan binatang atau ulat. Pendeknya maksud mereka hendak meruntuhkan Ka'bah tiadalah berhasil adanya." ${ }^{37}$

Dari surat al-Fiil di atas terdapat penggunaan kata "penyakit cacar". Penggunaan kata ini sangat terlihat jelas aspek ilmiah yang digunakan oleh Mahmud Yunus. Cara Mahmud Yunus memberikan penafsiran juga terkesan sangat akademis sekali, sesuai dengan yang ada di masa sekarang dan dapat diterima oleh masyarakat. Mahmud Yunus menggunakan penafsiran "hama", bahkan "penyakit cacar" yang sangat ilmiah dan banyak diketahui kalangan masyarakat, sehingga penafsirannya lebih mudah dipahami dan diterima khalayak umum.

\section{Surah Fushshilat ayat 13}

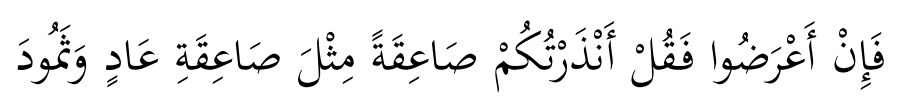

Artinya: "Jika mereka berpaling katakanlah: Aku beri peringatan kamu dan petir (siksa), seumpama siksa (yang menimpa kaum) 'Ad dan Tsamud”.

Mahmus Yunus menjelaskan ayat tersebut dalam kitab tafsirnya bahwa:

“Arti (صَاعِقَةً) yang jamaknya adalah (صواعق) ialah petir, geledek, halilintar, yaitu yang keras sekali di udara dan biasanya bersama kilat. Dalam Al-Qur'an ada tiga model penafsiran, yakni; pertama, 'mati' seperti 'maka matilah siapa

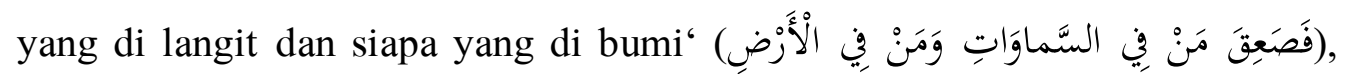
kedua, 'azab' seperti 'Aku beri peringatan kamu dan petir (siksa), seumpama

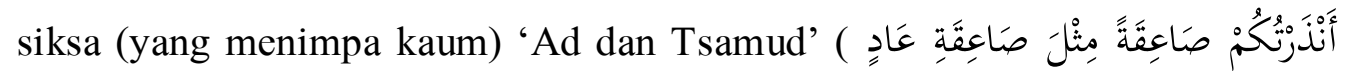

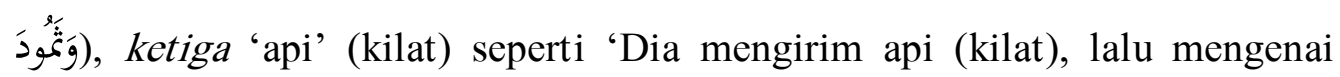
siapa yang dikehendakinya.' Sebenarnya ketiga-tiganya itu adalah hasil dari

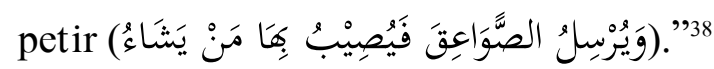

Begitupun dengan penafsiran yang terdapat dalam surah Fushshilat ini. Penjelasan yang dipaparkan oleh Mahmud Yunus mengenai "petir" disertai dengan penjelasan ilmiah yang dapat memberikan pemahaman yang lebih luas bagi para pembacanya. Hal ini memang sesuai dengan tujuan ditulisnya tafsir ini oleh Mahmud Yunus, yaitu untuk memberikan keterangan dan penjelasan tentang petunjuk-petunjuk Al-Qur'an agar dapat dimengerti dengan mudah, cepat, dan dapat dipraktikkan masyarakat dalam kehidupan sehari-hari.

\footnotetext{
${ }^{37}$ Mahmud Yunus, Tafsir Al-Qur'an al-Karim, 918-919.

${ }^{38}$ Mahmud Yunus, Tafsir Al-Qur'an al-Karim, 705.
} 
Surah al-Baqarah ayat 22

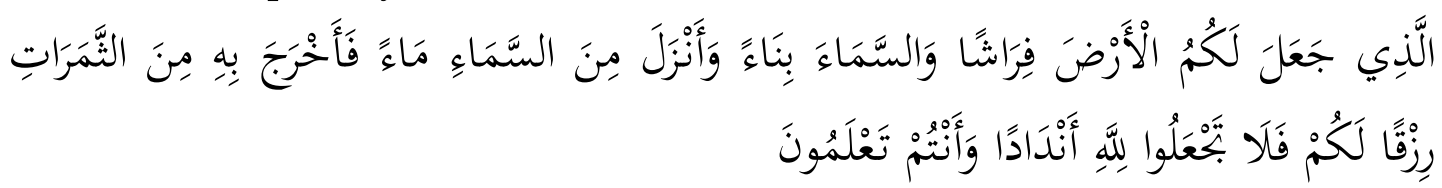

Artinya: “(Dia) yang menjadikan bumi untukmu sebagai tikar dan langit sebagai atap (bina) dan Dia menurunkan air hujan dari langit, lalu ditumbuhkanNya dengan air itu buah-buahan sebagai rezeki bagimu; sebab itu janganlah kamu menjadikan Allah beberapa sekutu, sedang kamu mengetahuinya”.

Dalam penafsirannya Mahmus Yunus menjelaskan ayat tersebut bahwa:

"Bumi ini seperti tikar. Sebagaimana tikar bisa diduduki, berdiri dan tidur di atasnya, begitu pulalah bumi ini, dapat kita perbuat yang sedemikian itu. Ada orang yang mengatakan bumi ini datar sebagai tikar. Tetapi itu menurut pandangan manusia saja, karena sebenarnya ia bulat. Tetapi karena sangat besar, maka memang sebagiannya menjadi datar. Bertambah besar suatu bulatan, bertambah luas datarannya." ${ }^{39}$

Penafsiran yang diberikan Mahmud Yunus mengenai bentuk bumi dalam ayat di atas, tidak bertentangan dengan teori ilmiah dan ilmu pengetahuan yang ada. Ia menjelaskan bahwa bumi itu berbentuk bulat, dan jika bumi ini dianggap datar, itu karena luasnya bulatan bumi itu sendiri, sehingga nampak luas datarannya, dan seakanakan bumi datar. Hal ini dituliskan Mahmud Yunus dalam penafsirannya agar dapat lebih mudah untuk diterima masyarakat, dan juga untuk menegaskan kesesuaian teori ilmu pengetahuan dan pernyataan ayat Al-Qur'an.

Dari contoh di atas, dapat terlihat bahwa penafsiran dari Mahmud Yunus dalam kitab tafsirnya memiliki nuansa ilmiah dan akademis, mulai dari penggunaan "hama" dan "penyakit cacar," penjelasan ilmiah tentang petir, hingga tentang bentuk bumi yang bulat.

\section{Corak Sosial}

Corak lain yang nampak dalam kitab ini dan membuatnya lebih terkesan akademis adalah corak sosial. Mahmud Yunus dalam karya tafsirnya sangat menonjolkan penyampaian nilai-nilai sosial. Hal ini merupakan sebuah jalan yang ditempuhnya untuk merealisasikan salah satu tujuan Mahmud Yunus dalam menulis kitabnya, yaitu untuk menyampaikan dakwah islamiah dan menjadikan ajaran dasar AlQur'an sebagai petunjuk universal. ${ }^{40}$

Adapun cara Mahmud Yunus dalam menonjolkan nilai-nilai sosial tersebut nampak melalui penafsirannya yang menggunakan adat dan tradisi sosial budaya, khususnya Minangkabau sebagai tempat kelahirannya. Ia menjadikan ungkapanungkapan adat Minangkabau sebagai sumber penafsiran guna menjelaskan makna dari ayat-ayat Al-Qur'an. Selain itu, dalam penafsirannya Mahmud Yunus juga mengkritik

\footnotetext{
${ }^{39}$ Mahmud Yunus, Tafsir Al-Qur'an al-Karim, 6.

${ }^{40}$ Sulaiman Ibrahim, Pendidikan dan Tafsir, 117. Lebih lanjut lihat Iskandar, "Tafsir Qur'an Karim Karya Mahmud Yunus," 8-10.
} 
sosial budaya yang ada dalam masyarakat Minang. ${ }^{41}$ Hal ini juga dilakukannya guna untuk memudahkan masyarakat memahami penafsirannya karena sesuai dengan sosial budaya di masyarakat.

Adapun contoh penafsiran corak sosial yang ada di kitab tafsir Mahmud Yunus ini, di antaranya:

\section{Surah al-Taubah ayat 79}

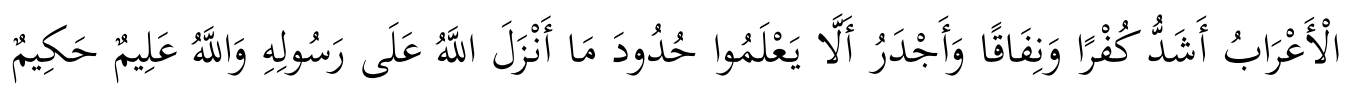

Artinya: "Orang-orang Arab Baduwi lebih kuat kekafiran dan kemunafikannya (dari pada orang kota) dan lebih patut, tidak mengetahui peraturan yang diturunkan Allah kepada rasul-Nya. Allah Maha Mengetahui, lagi Maha Bijaksana.

Adapun penafsiran Mahmud Yunus terhadap ayat di atas sebagai berikut:

"Bahwa sesungguhnya orang-orang Arab Baduwi itu kuat dengan kekafiran dan kemunafikannya, disebabkan oleh kurangnya pengetahuan tentang hukum-hukum yang diturunkan Allah kepada Rasul-Nya. Terlebih karena mereka tidak bisa membaca dan menulis untuk mendalami agama. Di kampung-kampung sendiri sebenarnya sangat sulit untuk menyampaikan kebenaran agama, disebabkan oleh jauhnya dari tempat pendidikan dan banyaknya buta huruf. Di situlah tugas kita sebenarnya memberantas buta huruf dan menyampaikan pendidikan agama di kampung-kampung yang sulit dijangkau. Tidak dipungkiri sebenarnya pelajaranpelajaran agama itu sendiri sudah tersebar di kampung-kampung dengan perantara tabligh-tabligh, namun pelajaran tersebut hanya didengarkan melalui tabligh saja dan akan mudah hilang karena jarang diulang. Padahal pepatah mengatakan "Lancar dikaji karena disebut, pasar jalan karena diturut" ${ }^{42}$

Dalam menafsirkan ayat tersebut, Mahmud Yunus memasukkan sebuah ungkapan atau pepatah daerah/ petuah lokal, yaitu "lancar dikaji karena disebut, pasar jalan karena diturut", yang mana maksudnya adalah kepandaian atau kemahiran didapat karena latihan. Ini merupakan salah satu ungkapan yang ada di wilayah Minangkabau saat itu. Guna menyampaikan nilai sosial yang ada dalam tafsir tersebut, Mahmud Yunus menggunakan bahasa yang lebih sesuai dengan keadaan sosial saat itu, sehingga dakwah islamiah yang ada di dalam ayat Al-Qur'an tersebut lebih mudah dipahami masyarakat.

\section{Surah al-Isra' ayat 26}

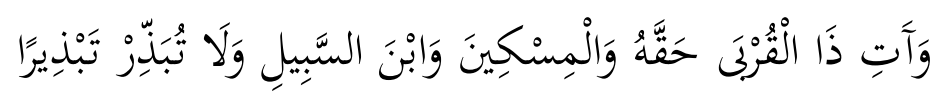

Artinya: "Berikanlah kepada karib-kerabat haknya masing-masing dan kepada orang miskin dan musafir dan janganlah kamu mubazir (pemboros) dengan semubazir-mubazirnya".

Dalam penafsirannya, Mahmud Yunus menjelaskan ayat yang ada di atas bahwa:

\footnotetext{
${ }^{41}$ Arif Iman Mauliddin, Unsur Lokal dalam Tafsir Al-Qur'an Karim, 79-81.

${ }^{42}$ Mahmud Yunus, Tafsir Al-Qur'an al-Karim, 280-281.
} 
"Hendaklah engkau berikan karib kerabatmu haknya masing-masing, umpamanya orang tua wajib memberikan nafkah kepada anak-anak dan istrinya, karena nafkah itu adalah hak mereka, yang wajib dibayarkan kepadanya. Tapi beribu kali sayang sebagian orang tua di negeri kita, lebih-lebih di Minangkabau tidak ada membayarkan kewajibannya kepada anak-anaknya, apalagi bila ia telah bercerai dengan ibu anaknya itu. Inilah suatu dosa yang terbesar di negeri kita, yang wajib kita bersama-sama membasminya, karena hal itu merusakkan masyarakat umum. Bukan sedikit anak-anak yang terlantar dan teraniaya, karena ditinggalkan orang tuanya bertahun-tahun lamanya dengan tidak diberi nafkah sedikit pun, seolaholah anak itu telah menjadi yatim piatu, sedangkan orang tuanya masih hidup. Insyaflah hai orang yang mempunyai anak!.”43

Terlihat dari penafsiran di atas bahwa Mahmud Yunus mengkritik adat atau kebiasaan Minangkabau khususnya, yaitu sebagian orang tua tidak diwajibkan untuk menafkahi anak-anaknya, apalagi jika kedua orang tua dari anak tersebut telah bercerai. Ini juga merupakan salah satu segi sosial budaya yang ada di wilayah Minangkabau. Penggunaan fenomena realitas sosial budaya yang ada saat itu, guna memudahkan untuk diterima dan dipahami oleh masyarakat, sehingga ajaran-ajaran yang ada di dalam Al-Qur'an lebih mudah untuk tersampaikan melalui usaha penafsiran Mahmud Yunus melalui cara tersebut.

Selain adat dan tradisi sosial budaya Minangkabau, Mahmud Yunus juga tak luput memasukkan unsur kebudayaan masyarakat Indonesia, mulai dari sistem religi, sistem mata pencaharian, sistem pengetahuan hingga organisasi sosial. ${ }^{44}$ Selanjutnya nuansa keindonesiaan yang terkait dengan dinamika keadaan sosial budaya masyarakat pun muncul dalam karyanya. ${ }^{45}$

Dari penafsiran dan penjelasan dengan memasukkan adat dan tradisi, serta dengan memasukkan unsur kebudayaan masyarakat Indonesia ini, tafsir Mahmud Yunus menjadi tafsir dengan konteks dan nuansa sosial keindonesiaan yang begitu akademis, yang mana penjelasan penafsirannya banyak menyasar latar budaya Indonesia dengan menghadirkan nilai-nilai maupun pesan moral yang sesuai dengan fenomena sosial budaya mayarakat Indonesia saat itu. Penjelasan penafsirannya ini tent unya disesuaikan dengan substansi dari ayat yang ia tafsirkan.

\section{Corak Intelektual}

Adapun corak lain yang mendukung sisi akademis tafsir Mahmud Yunus adalah corak intelektual yang ditandai dengan hadirnya karya ini di tengah-tengah masyarakat yang belum banyak mengerti akan bahasa kitab suci Al-Qur'an. Hal ini menunjukkan bahwa karya Mahmud sebagai sebuah medium dan perantara untuk mengantarkan generasi intelektual dalam membimbing mereka dan umat manusia untuk

\footnotetext{
${ }^{43}$ Mahmud Yunus, Tafsir Al-Qur'an al-Karim, 405.

${ }^{44}$ Anwar Mujahidin, "Hubungan Kebudayaan Tafsir Indonesia (Analisis Kisah Ibrahim dan Musa dalam Tafsir Karya Mahmud Yunus, Hamka, dan M. Quraish Shihab)," Jurnal Nun 3, no. 1 (2017):89116.

${ }^{45}$ Khairunnas Jamal, "Wawasan Keindonesiaan dalam Tafsir Al-Qur'an Al-Karim Karya Mahmud Yunus," Al-Fikra: Jurnal Ilmiah Keislaman, Vol. 16, No. 1, Tahun 2017, h. 43.
} 
mengamalkan ajaran Islam. ${ }^{46}$ Salah satu cara yang dilakukannya adalah dengan menambahkan ungkapan umum yang banyak diketahui dan dikenal oleh masyarakat Indonesia saat itu. Dengan menambahkan ungkapan umum, diharapkan masyarakat dan umat manusia lebih berintelek dalam memahami dan mengamalkan ajaran-ajaran Islam. Adapun contoh penafsiran corak intelektual yang ada di kitab ini, di antaranya:

\section{Surah al-Nisa' ayat 148}

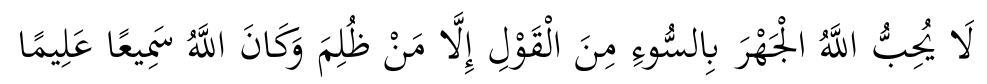

Artinya: "Allah tidak menyukai mengeraskan perkataan yang jahat,kecuali (bagi) orang yang teraniaya. Allah Maha Mendengar, lagi Maha Mengetahui”.

Mahmus Yunus menjelaskan ayat tersebut dalam kitab tafsirnya bahwa:

"Allah tidak menyukai perkataan jahat yang keluar dari mulut seseorang, yaitu perkataan bergunjing, mengumpat, mencela orang dsb. Karena perkataan demikian adalah bibit permusuhan, perpecahan, perkelahian, dan pembunuhan, sedang dalam agama Islam, kita harus selalu menjaga persatuan dan hubungan silaturrahim antara seseorang dan seseorang, antara golongan dengan golongan, antara partai dengan partai untuk menjaga kepentingan bersama. Sebab itulah kita harus menjaga lidah dari perkataan: "Mulutmu harimaumu" yang akan merengkah kepalamu maka jagalah ucapanmu, peliharalah mulutmu! Hanya orang yang teraniaya yang boleh mengeluarkan perkataan jahat, untuk mengadukan halnya kepada pengadilan, supaya terlepas dari keaniayaan itu." 47

Dari salah satu contoh penafsiran Mahmud Yunus di atas, ia menyisipkan sebuah peribahasa umum dalam penafsirannya, yaitu "mulutmu harimaumu" yang artinya keselamatan dan harga diri bergantung pada perkataan sendiri, atau tajamnya setiap perkataan yang diungkapkan akan mencelakakan diri sendiri. Ungkapan umum yang digunakannya ini berorientasi untuk mengintrodusir wawasan keindonesiaan dalam tafsirnya, yang mana hal ini bertujuan untuk meningkatkan generasi yang lebih berintelek dalam memahami ayat-ayat dan kandungan nilai-nilai yang ada di dalam AlQur'an sebagai kitab suci umat Islam sepanjang masa.

\section{Penutup}

Tafsir Al-Qur'an al-Karim karya Mahmud Yunus merupakan sebuah tafsir yang tergolong akademik karena banyaknya sisi-sisi akademis yang ia munculkan dalam penafsirannya. Aspek-aspek maupun sisi-sisi akademis tersebut nampak begitu terlihat dalam corak penafsiran yang ia gunakan. Mulai dari corak ilmiah, corak sosial hingga corak intelektual. Ketiga corak inilah yang menjadikan tafsir Mahmud Yunus begitu bersifat akademis. Corak ilmiah dalam penafsirannya ditunjukkan dengan mengaitkan bagian yang ditafsirkannya dengan ilmu pengetahuan yang sedang berkembang, sehingga penafsiran Mahmud Yunus terkesan menegaskan hubungan erat antara Al-

\footnotetext{
${ }^{46}$ Sulaiman Ibrahim, Pendidikan dan Tafsir, h. 117. Lebih lanjut lihat Iskandar, "Tafsir Qur' an Karim Karya Mahmud Yunus," h. 8-10.

${ }^{47}$ Mahmud Yunus, Tafsir Al-Qur'an al-Karim, h. 138-139.
} 
Qur'an dengan perkembangan ilmu pengetahuan dan teknologi. Adapun corak sosial dan corak intelektual lebih ditunjukkan Mahmud Yunus melalui penggunaan unsur ungkapan umum atau ungkapan bahasa, maupun tradisi, adat dan fenomena sosial budaya masyarakat Indonesia dalam penafsirannya.

\section{DAFTAR PUSTAKA}

Ahmad, Khader dkk. "Ketokohan Mahmud Yunus dalam Bidang Tafsir Al-Qur'an: Kajian terhadap Kitab Tafsir Quran Karim." The 2nd Annual International Qur'anic Conference, Centre of Quranic Research (CQR), 2012: 195-211.

Asra, Amaruddin dan M. Amursid. "Studi Tafsir al-Qur'an al-Karim Karya Mahmud Yunus." Jurnal Syahadah 3, no. 2, (2015): 1-19.

Baidan, Nashruddin dan Erwati Aziz. Metodologi Khusus Penelitian Tafsir. Yogyakarta: Pustaka Pelajar, 2016.

Perkembangan Tafsir Al-Qur'an di Asia Tenggara. Yogyakarta: Pustaka Pelajar, 2019.

Federspiel, Howard M. Kajian Al-Qur'an di Indonesia; dari Mahmud Yunus hingga Quraish Shihab. Terj. Tajul Arifin. Bandung: Penerbit Mizan, 1996.

Ghofur, Saiful Amin. Profil Para Mufasir al-Qur'an. Yogyakarta: Pustaka Insan Madani, 2008.

Hermawan, Tri, Putri Rafa Salihah, dan Muhammad Hafizh. "The Concept of Women's Dress in Tafsir Nusantara: A Comparative Study of Four Indonesian Exegeses." Ulumuna: Journal of Islamic Studies 21, no. 2 (2017): 370-390.

Ibrahim, Sulaiman. Pendidikan dan Tafsir; Kiprah Mahmud Yunus dalam Pembaruan Islam. Jakarta: LEKAS, 2011.

Ibrahim, Sulaiman. "Karakteristik Tafsir Al-Qur'an al-Karim Karya Mahmud Yunus." Jurnal Al-Ulum 11, no. 2 (2011): 397-420.

Igisani, Rithon. "Kajian Tafsir Mufassir di Indonesia."Jurnal Potret 22, no. 1 (2018): 11-31.

Iskandar. "Tafsir Qur'an Karim Karya Mahmud Yunus; Kajian atas Karya Tafsir Nusantara." Jurnal Suhuf 3, no. 1 (2010): 1-11.

Jamal, Khairunnas. "Wawasan Keindonesiaan dalam Tafsir Al-Qur'an Al-Karim Karya Mahmud Yunus." Al-Fikra: Jurnal Ilmiah Keislaman 16, no. 1 (2017): 28-44.

Mauliddin, Arif Iman. Unsur Lokal dalam Tafsir Al-Qur'an Karim Karya Mahmud Yunus. Tesis Mahasiswa UIN Sunan Kalijaga. Yogyakarta, 2019.

Mohammad, Herry dkk. Tokoh-Tokoh Islam yang Berpengaruh Abad 20. Jakarta: Gema Insani, 2008.

Mujahidin, Anwar. "Hubungan Kebudayaan Tafsir Indonesia (Analisis Kisah Ibrahim dan Musa dalam Tafsir Karya Mahmud Yunus, Hamka, dan M. Quraish Shihab).” Jurnal Nun 3, no. 1 (2017) : 89-116.

Rina, Malta. Pemikiran dan Karya-Karya Prof. Dr. H. Mahmud Yunus tentang Pendidikan Islam (1920-1982). Padang: Ilmu Sejarah Pascasarjana UNAND, 2011. 
Syarifuddin, M. Anwar dan Jauhar Azizy. "Mahmud Yunus: Pelopor Pola Baru Penulisan Tafsir Al-Qur'an Indonesia." Jurnal Ilmu Ushuluddin 2, no. 3 (2015): 323-343.

Taufikurrahman. "Dinamika Kajian Al-Qur'an di Indonesia." Ibn Abbas: Jurnal Ilmu Al-Qur'an dan Tafsir 2, no. 1 (2019): 213-230.

Yunus, Mahmud. Tarjamah Al-Qur'an al-Karim. Bandung: PT al-Ma'arif, 1967. Tafsir Al-Qur'an al-Karim. Djakarta: PT Hidakarya Agung, 1983.

Zulyadain. "Kerangka Paradigmatik Tafsir Al-Qur'an Al-Karim Karya Mahmud Yunus." Jurnal Al-A'raf 15, no 1 (2018): 127-146. 